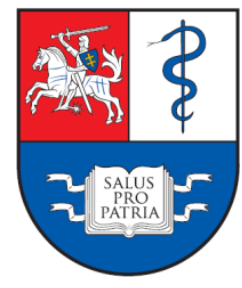

\title{
Do Lithuanian Military Conscripts Suffer from Hypovitaminosis D?
}

\author{
Romualdas Tomas Preikša, leva Gailytė, Lina Lašaitė, Rasa Verkauskienè \\ Institute of Endocrinology, Lithuanian University of Health Sciences, Kaunas, Lithuania
}

Hypovitaminosis D or vitamin D deficiency in healthy adults can result from inadequate exposure to sunlight or nutritional vitamin D insufficiency. However, the data of its clinical significance in healthy young adults is obscure.

The aim of the study was to evaluate vitamin D levels in Lithuanian male military conscripts and its association with PTH, osteocalcin and testosterone, body muscles and LBM percentage, as well as depression-dejection, tensionanxiety and psychological and physical quality of life.

Subjects and Methods. A total of 262 healthy Lithuanian male military conscripts (age range 18-26 years) were tested for vitamin D, PTH, osteocalcin and testosterone concentration and 155 (59.2\%) of them we rechecked one year later. Paralleled body composition was performed by the principle of bioelectrical impedance and evaluation of emotional state was assessed by the Profile of Mood Scale (POMS) as well as life quality was assessed by the short version of the life quality questionnaire of the WHO "WHOQOL-BREF".

Results. Primary vitamin D deficiency $(<20 \mathrm{ng} / \mathrm{ml})$ was detected in $95.0 \%$ and $96.7 \%$ when rechecked. Nevertheless vitamin D concentration was deficient, PTH and osteocalcin concentrations were normal.

Table 1. Vitamin D, PTH, osteocalcin and testosterone concentration in military conscripts at the beginning and the end of the military service

\begin{tabular}{|l|c|c|c|}
\hline & $\begin{array}{c}\text { Beginning } \\
\text { of Service }\end{array}$ & $\begin{array}{c}\text { End of } \\
\text { Service }\end{array}$ & $P$ \\
\hline Vitamin D (ng/mL) & $12.5 \pm 4.5$ & $10.4 \pm 4.9$ & $<0.001$ \\
\hline PTH (pmol/L) & $2.54 \pm 1.23$ & $2.70 \pm 1.10$ & $>0.5$ \\
\hline Osteocalcin $(\mathrm{ng} / \mathrm{mL})$ & $38.9 \pm 11.9$ & $40.4 \pm 12.8$ & $>0.5$ \\
\hline $\mathrm{T}(\mathrm{nmol} / \mathrm{L})$ & $16.0 \pm 4.1$ & $17.5 \pm 4.6$ & $<0.01$ \\
\hline
\end{tabular}

A weak Spearman rank order correlation $(r=-0.2 ; p=0.02)$ between vitamin $\mathrm{D}$ and PTH was detected when rechecked at the end of the military service.

Interestingly, no correlation between testosterone concentration and vitamin $\mathrm{D}$ has been detected in young healthy men, but at the end of their military service, testosterone concentration was significantly lower in the group of severe vitamin $D$ deficiency if compared with moderate (Table 2):
Table 2. Testosterone concentration, muscle and lean body mass percentage in severe and moderate vitamin $D$ deficiency

\begin{tabular}{|l|c|c|c|}
\hline $\begin{array}{l}\text { Vitamin D } \\
\text { concentration }\end{array}$ & $\begin{array}{c}<\mathbf{1 0} \\
\mathbf{n g} / \mathrm{mL}\end{array}$ & $\begin{array}{c}\mathbf{1 0 - 2 0} \\
\mathrm{ng} / \mathrm{mL}\end{array}$ & $\mathbf{P}$ \\
\hline $\mathrm{T}(\mathrm{nmol} / \mathrm{I})$ & $16.7 \pm 4.1$ & $18.6 \pm 5.1$ & 0.025 \\
\hline Muscle (\%) & $57.3 \pm 5.6$ & $59.3 \pm 5.9$ & 0.057 \\
\hline Lean mass (\%) & $61.7 \pm 6.0$ & $63.7 \pm 6.4$ & 0.073 \\
\hline
\end{tabular}

At the end of the study, vitamin $D$ concentration correlated with muscles $(r=0.2 ; p=0.03)$ and LBM percentage $(r=0.2 ; p=0.04)$

Table 3. Correlation between vitamin D concentration and psychological issues

\begin{tabular}{|l|c|c|}
\hline \multirow{2}{*}{} & \multicolumn{2}{|c|}{ Vitamin D } \\
\cline { 2 - 3 } & $r$ & $P$ \\
\hline Profile of Mood Scale \\
\hline Tension-anxiety & -0.14 & 0.03 \\
\hline Depression-dejection & -0.19 & 0.03 \\
\hline Quality of Life & \multicolumn{2}{|}{} \\
\hline Physical health & 0.27 & 0.001 \\
\hline Psychological health & 0.29 & 0.001 \\
\hline
\end{tabular}

\section{Conclusion:}

1. Almost all Lithuanian male military conscripts were detected to have vitamin D deficiency. Even more greater vitamin D deficiency at the end of the military service neither resulted in increase in PTH nor in osteocalcin concentration.

2. Vitamin D deficiency at the end of the study correlated with a smaller amount of body muscles and LBM percentage and decreased testosterone concentration.

3. A lower vitamin D concentration conditioned depression-dejection and tension-anxiety as well as decreased psychological and physical quality of life. 